\title{
Pharmacokinetics and safety of glimepiride at clinically effective doses in diabetic patients with renal impairment
}

\author{
B. R osenkranz ${ }^{1}$, V. Profozic ${ }^{2}$, Z. M etelko², V. M rzljak², C. L ange' ${ }^{1}$, V. M alerczyk ${ }^{1}$ \\ ${ }^{1}$ H oechst A G, Frankfurt, G ermany \\ ${ }^{2}$ Institute for D iabetes, E ndocrinology and M etabolic D iseases, Vuk V rhovac, Zagreb, Croatia
}

Summary The pharmacokinetics, efficacy and safety of glimepiride were investigated in a single- and a multiple-dose open study in patients with non-insulin-dependent diabetes mellitus and renal impairment and an initial creatinine clearance above $10 \mathrm{ml} /$ min. Patients were divided into three groups with creatinine clearance above $50 \mathrm{ml} / \mathrm{min}, 20-50 \mathrm{ml} / \mathrm{min}$ and under $20 \mathrm{ml} / \mathrm{min}$. Fifteen fasting patients received a single dose of $3 \mathrm{mg}$ glimepiride and serial blood and urine samples were taken over $24 \mathrm{~h}$ for pharmacokinetic and efficacy analyses. A further 16 patients received glimepiride over a 3-month period, an initial dose of $1 \mathrm{mg}$ glimepiride being adjusted within the range 1 to $8 \mathrm{mg}$ to achieve good glucose control. Pharmacokinetic evaluation was done on day 1 and after 3 months. Mean relative total clearance and mean volume of distribution of both single $(41.6 \mathrm{ml} /$ min and 8.47 litres, respectively, when creatinine clearance was above $50 \mathrm{ml} / \mathrm{min}$ ) and multiple doses of glimepiride increased in proportion to the degree of renal impairment (to $91.1 \mathrm{ml} / \mathrm{min}$ and 14.98 litres, respectively, when creatinine clearance was below $20 \mathrm{ml} / \mathrm{min}$, single dose), whereas the terminal halflife and mean time remained unchanged. L ower relative total clearance and renal clearance of both glimepiride metabolites correlated significantly with lower creatinine clearance values. Of the 16 patients 12 required between 1 and $4 \mathrm{mg}$ glimepiride to stabilize their fasting blood glucose. G limepiride was well-tolerated and there were no drug-related adverse events. In conclusion glimepiride is safe, effective and has clearly-definable pharmacokinetics in diabetic patients with renal impairment. The increased plasma elimination of glimepiride with decreasing kidney function is explainable on the basis of altered protein binding with an increase in unbound drug. [D iabetologia (1996) 39: 1617-1624]

Keywords Pharmacokinetics, efficacy, safety, glimepiride, non-insulin-dependent diabetes mellitus, renal impairment.
First generation sulphonylureas such as tolbutamide, acetohexamide and chlorpropamide are eliminated almost exclusively by renal excretion $[1,2]$ which

Corresponding author: Dr. B. R osenkranz, H oechst A G, Corporate Clinical Pharmacology, D-62926 Frankfurt am M ain, Germany

A bbreviations: $t_{1 / 2}$, Terminal half-life; $C_{\max }$, maximum concentration; $t_{\max }$, time to maximum concentration, $A \cup D C$, area under the data curve extrapolated to infinity; M T, mean time; CL/ $f$, relative total clearance; $V_{\text {sys }} / f$, relative volume of distribution; $C L_{C R}$, creatinine clearance; $C L / f_{m}$, apparent clearance of metabolite; $C L_{\text {ren, }}$ renal clearance; NIDDM, non-insulin-dependent diabetes mellitus; $M$, multiple-dose study; $S$, singledose study. makes them unsuitable for use in patients with kidney failure [3]. Most second generation sulphonylureas are metabolised and the metabolites are excreted in the urine. Sulphonylureas are normally given to diabetic patients over a long period of time during which a decrease in kidney function might occur as a result of the disease. I mpaired kidney function may lead to metabolite accumulation which might influence the pharmacokinetics of the drug, but also affect the therapeutic response since the metabolites can have pharmacological activity. Glyburide (glibenclamide) clearance is unaffected by kidney function [1], as is that of glipizide, but accumulation of their metabolites has been reported $[4,5]$. G limepiride is a new 
hypoglycaemic sulphonylurea, with the advantage of being completely bioavailable [6], being effective at low doses in patients with non-insulin-dependent diabetes mellitus (NID D M ) and showing linear pharmacokinetics [7]. As with the other sulphonylureas, glimepiride appears to lower blood glucose levels by stimulating insulin release from the pancreas $[8,9]$. Elimination of glimepiride is primarily by metabolism to a hydroxy derivative, $\mathrm{M} 1$, and a carboxy derivative, $M 2$, which are then excreted in the urine. A nimal studies have shown M 1 to have a hypoglycaemic effect of approximately one third that of the parent compound whereas M 2 exhibited no pharmacological activity [10].

The objective of the present studies was to investigate the pharmacokinetics, efficacy and safety, of a single $3 \mathrm{mg}$ dose and of multiple blood glucose stabilizing doses (1-8 $\mathrm{mg}$ ) of glimepiride in patients with NIDDM and with varying degrees of renal impairment.

\section{Subjects, materials and methods}

Subjects. Subjects were recruited from The Institute of $D$ iabetes, E ndocrinology and M etabolic D iseases, Vuk V rhovac, Z agreb, Croatia and The D epartment of Nephrology, U niversity Clinics, G ent, B elgium. The studies were carried out in accordance with the declaration of $\mathrm{Helsinki}$ and were approved by the relevant ethical committees. Prior to obtaining written or oral consent, patients were informed of the nature, scope and possible outcomes of the trial.

E ligible adults had NID D M treated with insulin for the single-dose study (S), and treated for at least 4 weeks with either insulin ( $\leq 24$ units daily) or oral hypoglycaemic agents for the multiple-dose study $(M)$; they were aged between $44-75$ years with a creatinine clearance above $10 \mathrm{ml} / \mathrm{min}$. For patients to be eligible for the M study, good metabolic control was required. This was defined as less than a $20 \%$ variation of $\mathrm{HbA}_{1 \mathrm{c}}$ on two occasions prior to the study and insulin-treated patients were required to demonstrate sufficient insulin secretion capacity, as assessed by fasting C-peptide baseline level and/or increase after i.v. injection of $1 \mathrm{mg}$ glucagon, determined before, 6 and $20 \mathrm{~min}$ after injection. Insulin secretion capacity was also tested in several subjects on oral agents.

Exclusion criteria included surgery in the previous 6 weeks, alcohol abuse, recent participation in a drug trial, treatment with a potentially toxic drug, history of hypersensitivity to the trial or structurally related drug, a history of or presence of a clinically significant acute illness, gastrointestinal, liver or kidney disease or other severe concomitant disease or any condition known to interfere with the absorption, distribution, metabolism or excretion of drugs (except those related to kidney disease or diabetes). Women of child-bearing potential, patients undergoing kidney dialysis or who had undergone kidney transplant or those with a haematocrit less than $18 \%$ were not included. Patients with any contraindication to sulphonylurea treatment or requiring co-medication with any sulphonylurea or a drug with the potential to interact with sulphonylureas or with salicylates were also excluded.

In both studies, patients were selected and grouped according to their baseline creatinine clearance values. During the week preceding the $S$ study and in the 4 weeks preceding the
M study all subjects underwent a full physical examination and documentation of medical history, which included vital signs, creatinine clearance and ECG. Fasting blood and urine samples were collected and analysed for routine haematology, clinical chemistry, including fasting blood glucose and creatinine clearance and urinalysis.

\section{Single-dose study}

Treatment and clinical assessments. On the pre-study day insulin and the usual diet were permitted, patients were not allowed alcohol or beverages containing xanthine derivatives for $24 \mathrm{~h}$ before and until $24 \mathrm{~h}$ after drug administration. Specifically excluded drugs were not permitted for $24 \mathrm{~h}$ prior to and until $24 \mathrm{~h}$ after the study medication, other concomitant medication was reduced to a minimum during the trial period, insulin was permitted if clinically indicated, i. e. blood glucose over $150 \mathrm{mmol} / \mathrm{l}$ or acetonuria.

$\mathrm{O} n$ the study day a single dose of $3 \mathrm{mg}$ glimepiride was given after an overnight fast with $150 \mathrm{ml}$ mineral water or decaffeinated coffee. Subjects received breakfast 30 min after administration and light meals at $2-3 \mathrm{~h}$ intervals throughout the day. Subjects remained recumbent for $4 \mathrm{~h}$ and under medical supervision for at least $48 \mathrm{~h}$ post-administration. B ody weight and vital signs were measured and blood and urine samples for standard analyses, including frequent glucose determinations, taken immediately before and $24 \mathrm{~h}$ after administration of the drug. A dverse events were monitored and recorded during the study.

P harmacokinetic assessments. B lood samples were taken via an indwelling cannula before medication $(0 \mathrm{~h} *)$, then at $0.5,1^{*}$, $1.5,2,2.5,3^{*}, 4,5^{*}, 7^{*}, 9^{*}, 11^{*}, 13^{*}, 16^{*}, 19^{*}, 21^{*}, 24^{*}, 34^{*}$, $48^{*} \mathrm{~h}$ after drug administration. $\mathrm{G}$ lucose was determined in serum from samples denoted with an asterisk. C reatinine was determined in serum from samples collected before, 4, 9, 24, 34, and $48 \mathrm{~h}$ after drug administration. C-peptide was measured in serum from samples collected before and at $2 \mathrm{~h}$ after drug administration. Blood samples for pharmacokinetic assessment, except those taken at 16, 19 and 21 hours, were centrifuged, frozen and subsequently analysed for glimepiride and its metabolites $\mathrm{M} 1$ and $\mathrm{M} 2$.

Patients voided their bladders before administration of the study drug to provide a baseline sample. Subsequently urine was collected in the following fractions: 0-4, 4-9, 9-24 and 24-48 $\mathrm{h}$ after administration. Total volume was recorded, creatinine measured and samples stored frozen, for determination of glimepiride metabolites M 1 and M 2 in each fraction.

\section{M ultiple-dose study}

Treatment and clinical assessments. The initial dose of glimepiride was $1 \mathrm{mg}$. This dose was adjusted during the study to achieve sufficient metabolic control as assessed by fasting blood glucose levels; the increasing daily doses were 1, 2, 3, 4, 6 , and $8 \mathrm{mg}$. The decision to adjust a daily dose was made 47 days after the first dose of glimepiride and subsequently every 4-7 days after each dose adjustment for the total study period of 3 months. A fasting blood glucose level equal to or less than $8.32 \mathrm{mmol} / \mathrm{l}$ was acceptable in this patient population and necessitated no dose adjustment. A level of 8.32$9.99 \mathrm{mmol} / \mathrm{l}$ could be considered acceptable provided that the investigator felt that a lower blood glucose concentration imposed too great a risk of hypoglycaemia. If fasting blood 
glucose was above $11.09 \mathrm{mmol} / \mathrm{l}$ on two successive occasions after the $8 \mathrm{mg}$ dose had been reached the patient was withdrawn from the study. Medication was always taken with tea or coffee before breakfast. Patients remained under medical supervision as required during the dose titration period. Compliance was checked by the return of medication.

On the pre-study day, usual medication and diet were permitted. A fter an overnight fast, body weight and vital signs were recorded and urine and blood samples collected for standard safety and creatinine clearance assessments. U sual medication was discontinued and $1 \mathrm{mg}$ glimepiride was given. $\mathrm{Pa}$ tients remained under medical supervision for the duration of the pharmacokinetic studies. Blood and urine samples were taken for standard laboratory and creatinine assessments, together with a physical examination and measurement of vital signs after 1, 2 and 3 months. A dverse events were monitored and recorded throughout the study.

P harmacokinetic assessments. Venous blood samples for pharmacokinetic and dynamic analysis were taken via an indwelling cannula before medication, and $0.5,1,2,3,4,7,9,13$ and $24 \mathrm{~h}$ after medication on the first and last (85th) day of the study and immediately frozen for analysis of glimepiride and metabolites.

Patients emptied their bladders prior to dosing to provide a baseline urine sample on pharmacokinetic days. Subsequently, total volumes of urine were collected at $0-4,4-8,8-12$, and $12-24 \mathrm{~h}$ after medication, the volume recorded and samples were stored at least $-15^{\circ} \mathrm{C}$ prior to analysis for creatinine and metabolites $\mathrm{M} 1$ and $\mathrm{M} 2$.

Glimepiride and its metabolites M 1 and M 2 were determined using an established HPLC method [11] at Hoechst A G (Pharma R esearch, Frankfurt, G ermany). D etection limits were $5 \mathrm{ng} / \mathrm{ml}$ for glimepiride and M 2 (serum), $10 \mathrm{ng} / \mathrm{ml}$ for $M 1$ (serum) and $50 \mathrm{ng} / \mathrm{ml}$ for both metabolites in urine.

D etermination of the pharmacokinetic model independent parameters was carried out using the HOEREP program (D. $B$ rockmeier, H oechst A G). Terminal half-life $\left(t_{12}\right)$ was determined from the linear part of the concentration vs time curves in log-linear representation. $C_{\max }$ and $t_{\max }$ were read from the original data. The area under the data curve extrapolated to infinity (A U D C) was calculated using the trapezoid rule. M ean time (MT), relative total clearance $(\mathrm{CL} / \mathrm{f})$ and relative volume of distribution $\left(\mathrm{V}_{\text {syy }} / \mathrm{f}\right)$ were calculated according to standard formulae. Pharmacokinetic data of glimepiride metabolites were determined similarly. $\mathrm{CL} / \mathrm{f}, \mathrm{V}_{\text {syg }} / \mathrm{f}, \mathrm{t}_{1 / 2}$ and $\mathrm{MT}$ were plotted against creatinine clearance for all subjects, regression analysis was performed for $\mathrm{CL} / \mathrm{f}$ and $\mathrm{V}_{\text {sys }} / \mathrm{f}$.

Pharmacokinetic data from the first and last day (day 85) of the $M$ study were fitted simultaneously taking into account the individual dosing schemes thereby producing one value for each pharmacokinetic parameter with the exception of renal clearance. In most cases in this study, a two-compartment model was used to approximate glimepiride concentrations and a one-compartment model for the metabolites.

$U$ rinary excretion of the glimepiride metabolites was calculated for each fraction and this data was used to produce a cumulative total and, after appropriate molecular weight correction, this total was expressed as a percentage of the total glimepiride dose. $R$ enal clearance was estimated where feasible.

Creatinine clearance $\left(C L_{c r}\right)$ data used in the final evaluation was that which was recorded during the study period and not that used for selection. It was calculated as a weighted mean of all available measurements.

E fficacy and dynamic variables. Serum glucose, insulin and Cpeptide profiles were measured in the timed serial serum
Table 1. D emographic characteristics of subjects

\begin{tabular}{lll}
\hline & Single-dose study & M ultiple-dose study \\
\hline M ale/female $(\mathrm{n})$ & $7 / 8$ & $9 / 10$ \\
A ge (years) & $57(44-70)$ & $62.3(49-75)$ \\
Weight $(\mathrm{kg})$ & $71.4(56.0-90.3)$ & $78.1(63.8-98.0)$ \\
\hline
\end{tabular}

Values are mean (range)

samples taken for pharmacokinetic profiles on day 1 and at the end of the study (day 85). Serum creatinine was measured in the 0 and 24-h samples on both occasions.

Fasting blood samples were taken before medication on day 1 and weekly for the first 2 months, then every 2 weeks for the final month. Blood samples were centrifuged and serum samples were stored at $4^{\circ} \mathrm{C}$ for creatinine and glucose determinations or frozen prior to analysis.

Fasting whole blood glucose and serum creatinine were determined before medication, weekly for 2 months then every 2 weeks. Where possible patients used home-glucose monitoring to assess fasting blood glucose levels once every 2 days and ketoacidosis was assessed daily with urine sticks. The investigator was contacted if fasting blood glucose was out of the range of 5.55-11.09 mmol/l. Blood glucose profiles using timed capillary blood samples were assessed at five time points on the pre-trial day and after 1, 2, and 3 months. Fasting capillary blood glucose was monitored by patients every 2 days.

$\mathrm{B}$ lood samples for $\mathrm{H} \mathrm{bA}_{1 \mathrm{c}}$ analysis were taken on day 1 and after 1,2 and 3 months.

\section{Results}

Patient characteristics. Fifteen patients were enrolled into the single-dose study, for which demographic details are given in Table 1 and grouping according to baseline $C L_{c r}$ in Table 2. A Il patients were diabetic and where kidney disease was present the aetiology was diabetic nephropathy. A dditional diseases reported included cholecystectomy, cholelithiasis, hypertension and peripheral vascular disease. A II subjects in the $S$ group had been under treatment with insulin. Several patients took glibenclamide on the prestudy day which was not in accordance with the protocol. No relevant findings were reported during the physical examination or ECG.

$\mathrm{N}$ ineteen patients were enrolled into the multipledose study, for which demographic details are given in Table 1 and grouping according to baseline $C L_{C R}$ in Table 2. Three patients dropped out prior to completion, two due to poor metabolic control, and one for personal reasons; all three were included in the safety assessments. A II patients had NIDDM with kidney disease mostly due to diabetic nephropathy and all subjects had been treated with oral hypoglycaemic agents. O ther renal diseases also diagnosed included nephroangiosclerosis, chronic pyelointerstitial nephritis, nephrolithiasis, nephropathia gravidarum and renal cyst. $O$ ther diseases included diabetic retinopathy, neuropathy, angiopathy, hypertension, ischaemic heart disease and ventricular hypertrophy. The physical examination revealed no 

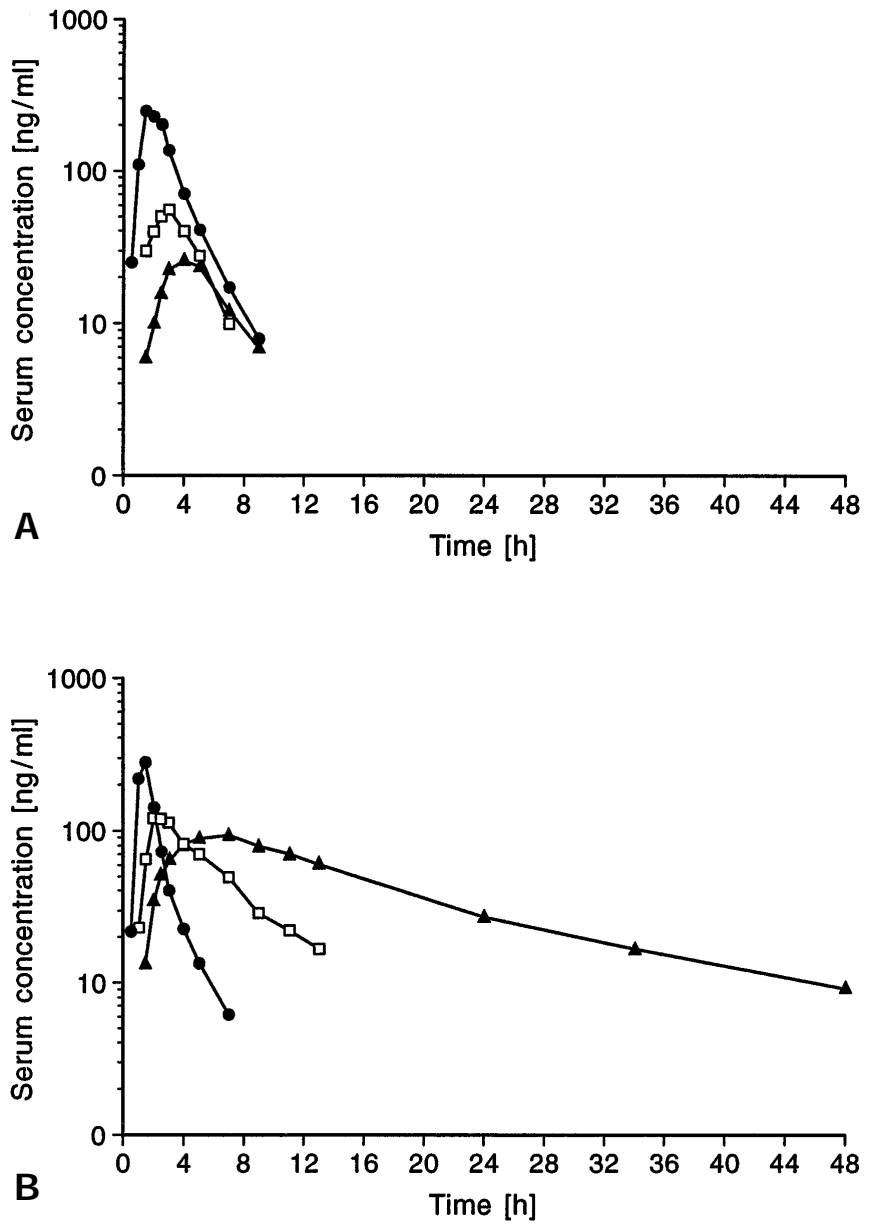

Fig. 1.A , B. Serum concentration-time curves of glimepiride and its two metabolites in a patient with normal creatinine clearance $(\mathbf{A})$ and in a patient with creatinine clearance $<20 \mathrm{ml} / \mathrm{min}$ (B) after a single $3 \mathrm{mg}$ dose. glimepiride, $\square$ metabolite $\mathrm{M} 1, \boldsymbol{\Delta}$ metabolite $\mathrm{M} 2$

relevant findings, all patients were judged to show good metabolic control following fasting C-peptide assessment and the glucagon test. O ne subject received insulin from the first study day as needed.

Pharmacokinetics. There were no relevant differences between creatinine clearance, serum creatinine levels or pharmacokinetic assessments made on the 2 study days of the $M$ study, so results were pooled for each subject. A s the glimepiride doses for the $M$ study varied, $C_{\max }, t_{\max }$ and A UDC were excluded. The pharmacokinetic parameters for glimepiride and its metabolites $\mathrm{M} 1$ and $\mathrm{M} 2$ after both single and multiple dosing are given in Table 2 . The relationships between kidney function and pharmacokinetic parameters are illustrated in Figs. 1-4. A s expected, serum metabolite concentrations were prolonged in patients with renal impairment (Fig. 1).

Taken together, the data indicate that relative total clearance of glimepiride tended to increase with impaired kidney function (Iow $C L_{C R}$ ) on both $S$ and $M$
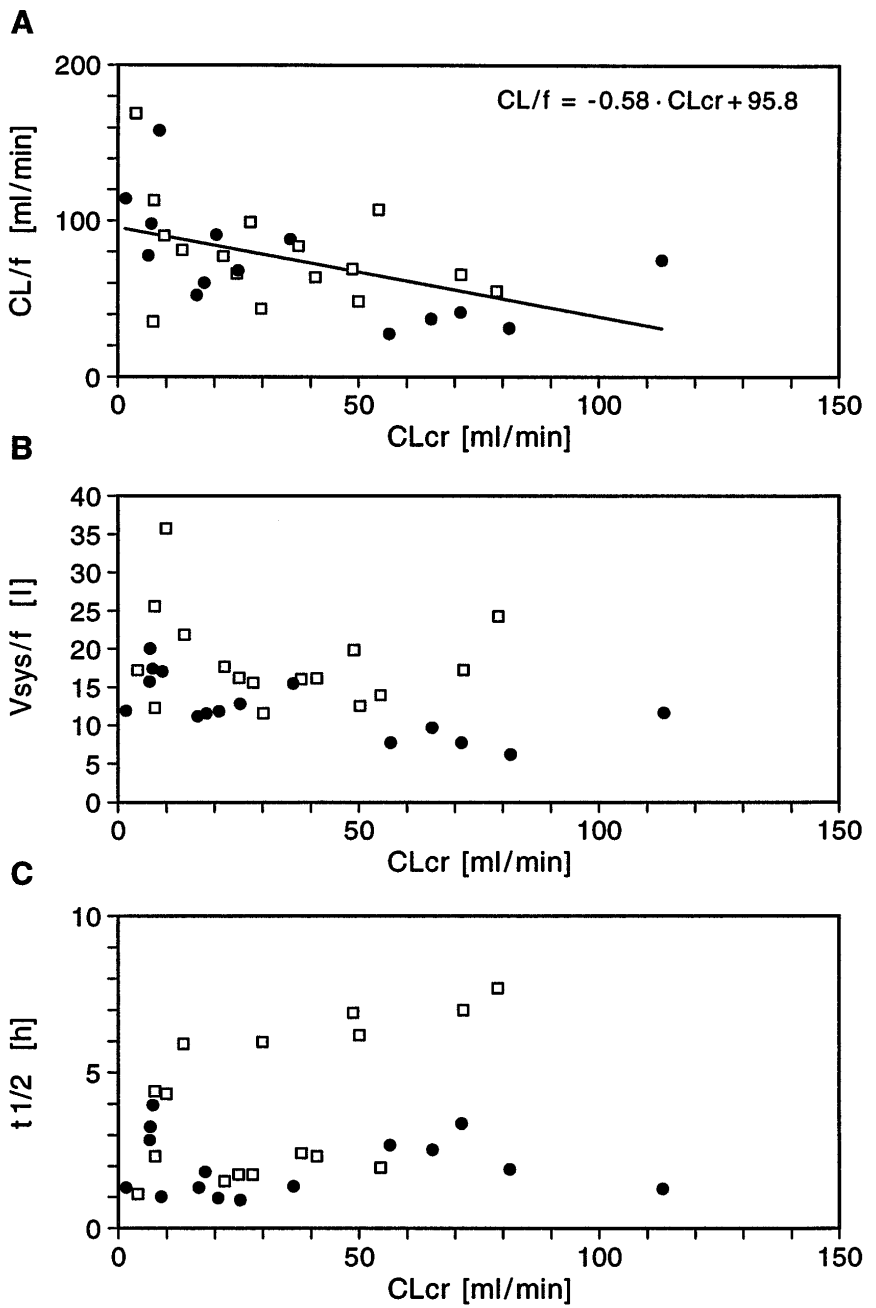

Fig. 2.A - C. R egression between creatinine clearance $\left(C L_{C R}\right)$ and relative and total clearance $(C L / f)(A)$, relative volume distribution $\left(V_{\text {sys }} / f\right)(B)$, or terminal half-life $\left(t_{1 / 2)}(C)\right.$ of glimepiride from multiple and single dose studies. single-dose study, $\square$ multiple-dose study

dosing, though regression was not statistically significant (Fig. 2). While the relative volume of distribution $\left(V_{\text {sys }} f\right)$ also tended to increase with renal impairment on single dosing (Table 2 ), this could not be confirmed on multiple dosing (Table 2).

The $t_{1 / 2}$ and $M T$ of glimepiride were unchanged in impaired kidney function on single dosing and were highly varied on multiple dosing (Fig. 2 and Table 2).

E limination of the glimepiride metabolites was impaired in kidney disease. R elative total clearance was linearly related to $C L_{C R}$ (Figs. 3 and 4), and total urinary excretion of the metabolites $\mathrm{M} 1$ and $\mathrm{M} 2$ was reduced, as reflected by a tendency for $\mathrm{t}_{1 / 2}$ and $\mathrm{C}_{\max }$ to increase with decreasing $\mathrm{CL}_{\mathrm{CR}}$ (Table 2; Figs. 3 and 4).

E fficacy (multiple-dose study only). In 12 of the 16 patients in this study sufficient metabolic control was reached with dosages between 1 and $4 \mathrm{mg}$. The effective dose of glimepiride required to lower blood 
Table 2. Pharmacokinetic characteristics of glimepiride and its metabolites in patients with NIDDM and impaired renal function after a single $3 \mathrm{mg}$ dose (S) or after multiple variable effective doses (M )

\begin{tabular}{|c|c|c|c|c|c|c|}
\hline \multirow[t]{2}{*}{ Parameter } & \multicolumn{2}{|c|}{$\begin{array}{l}\text { Group } 1 \\
\mathrm{CL}_{\mathrm{cr}}>50 \mathrm{ml} / \mathrm{min}\end{array}$} & \multicolumn{2}{|c|}{$\begin{array}{l}\text { G roup } 2 \\
\mathrm{CL}_{\mathrm{cr}} 20-50 \mathrm{ml} / \mathrm{min}\end{array}$} & \multicolumn{2}{|c|}{$\begin{array}{l}\text { Group } 3 \\
\mathrm{CL}_{\mathrm{cr}}<20 \mathrm{ml} / \mathrm{min}\end{array}$} \\
\hline & $\mathrm{s}$ & $M$ & $\mathrm{~s}$ & $M$ & $\bar{S}$ & $M$ \\
\hline $\begin{array}{l}\mathrm{n} \\
\mathrm{CL} L_{\mathrm{cr}}(\mathrm{ml} / \mathrm{min})\end{array}$ & $\begin{array}{l}5 \\
77.7 \pm 21.9\end{array}$ & $\begin{array}{l}4 \\
63.9 \pm 13.8\end{array}$ & $\begin{array}{l}3 \\
27.4 \pm 8.0\end{array}$ & $\begin{array}{l}7 \\
33.2 \pm 9.7\end{array}$ & $\begin{array}{l}7 \\
9.4 \pm 5.9\end{array}$ & $\begin{array}{l}5 \\
8.5 \pm 3.6\end{array}$ \\
\hline $\begin{array}{l}\text { G limepiride } \\
C_{\max }(\mathrm{ng} / \mathrm{ml}) \\
\mathrm{t}_{\max }(\mathrm{h}) \\
\mathrm{A} \cup \mathrm{C}\left(\mathrm{ng} \cdot \mathrm{h} \cdot \mathrm{ml}^{-1}\right) \\
\mathrm{CL} / \mathrm{f}(\mathrm{ml} / \mathrm{min}) \\
\mathrm{V}_{\text {sys }} / \mathrm{f}(\mathrm{l}) \\
\mathrm{t}_{1 / 2}(\mathrm{~h}) \\
M T(\mathrm{~h})\end{array}$ & $\begin{array}{c}359.2 \pm 98.3 \\
1.9 \pm 0.2 \\
1357 \pm 452 \\
41.6 \pm 18.5 \\
8.47 \pm 2.05 \\
2.28 \pm 0.79 \\
3.6 \pm 0.9\end{array}$ & $\begin{array}{l}- \\
- \\
- \\
68.1 \pm 26.4 \\
16.9 \pm 5.3 \\
5.6 \pm 3.0 \\
4.6 \pm 2.2\end{array}$ & $\begin{array}{c}205.3 \pm 29.0 \\
2.7 \pm 1.3 \\
622 \pm 106 \\
81.1 \pm 12.8 \\
13.36 \pm 1.89 \\
1.06 \pm 0.23 \\
2.8 \pm 0.5\end{array}$ & $\begin{array}{l}- \\
- \\
- \\
71.4 \pm 17.5 \\
16.1 \pm 2.5 \\
3.2 \pm 2.2 \\
3.9 \pm 0.8\end{array}$ & $\begin{array}{c}194.0 \pm 42.4 \\
2.2 \pm 1.0 \\
622 \pm 226 \\
91.1 \pm 36.5 \\
14.98 \pm 3.47 \\
2.19 \pm 1.13 \\
3.0 \pm 1.0\end{array}$ & $\begin{array}{l}- \\
- \\
- \\
97.8 \pm 48.7 \\
22.6 \pm 8.9 \\
3.6 \pm 1.9 \\
4.5 \pm 1.9 \\
{[n=3]}\end{array}$ \\
\hline $\begin{array}{l}\text { Total urinary metabolite } \\
\text { excretion (M } 1 \text { - M 2) ( } \% \text { dose) }\end{array}$ & $44.4 \pm 28.0$ & $40.4 \pm 7.2$ & $21.9 \pm 12.8$ & $26.2 \pm 11.8$ & $9.3 \pm 10.6$ & $10.6 \pm 8.2$ \\
\hline $\begin{array}{l}\text { M etabolite M } 1 \\
\mathrm{C}_{\max }(\mathrm{ng} / \mathrm{ml}) \\
\mathrm{t}_{\max }(\mathrm{h}) \\
\mathrm{CL} / \mathrm{f}_{\mathrm{m}}(\mathrm{ml} / \mathrm{min}) \\
\mathrm{t}_{1 / 2}(\mathrm{~h}) \\
\mathrm{CL}_{\text {ren }}(\mathrm{ml} / \mathrm{min})\end{array}$ & $\begin{array}{c}70.8 \pm 14.0 \\
3.8 \pm 0.8 \\
132.1 \pm 66.4 \\
2.79 \pm 0.86 \\
49.6 \pm 48.9\end{array}$ & $\begin{array}{l}- \\
- \\
100.2 \pm 30.4 \\
3.75 \pm 1.3 \\
31.8 \pm 21.1\end{array}$ & $\begin{array}{c}93.0 \pm 12.5 \\
3.2 \pm 0.8 \\
107.0 \pm 33.7 \\
2.32 \pm 0.93 \\
9.2 \pm 7.0\end{array}$ & $\begin{array}{l}- \\
- \\
80.6 \pm 21.1 \\
3.96 \pm 1.8 \\
11.8 \pm 8.3 \\
{[n=6]}\end{array}$ & $\begin{array}{c}103.6 \pm 24.1 \\
4.1 \pm 2.3 \\
67.5 \pm 39.6 \\
4.88 \pm 2.92 \\
4.9 \pm 7.5\end{array}$ & $\begin{array}{l}- \\
- \\
59.7 \pm 33.3 \\
8.0 \pm 4.6 \\
2.1 \\
{[n=1]}\end{array}$ \\
\hline $\begin{array}{l}\text { M etabolite M 2 } \\
C_{\max }(\mathrm{ng} / \mathrm{ml}) \\
\mathrm{t}_{\max }(\mathrm{h}) \\
\mathrm{CL} / \mathrm{f}_{\mathrm{m}}(\mathrm{ml} / \mathrm{min}) \\
\mathrm{t}_{1 / 2}(\mathrm{~h})\end{array}$ & $\begin{array}{c}21.8 \pm 8.5 \\
4.8 \pm 1.5 \\
306.5 \pm 63.6 \\
4.91 \pm 2.94\end{array}$ & $\begin{array}{l}- \\
- \\
184.2 \pm 51.8 \\
\quad 3.5 \pm 1.1 \\
{[n=3]}\end{array}$ & $\begin{array}{c}42.0 \pm 2.6 \\
5.7 \pm 1.2 \\
140.8 \pm 36.5 \\
3.06 \pm 0.50\end{array}$ & $\begin{array}{l}- \\
- \\
111.9 \pm 38.3 \\
\quad 4.2 \pm 1.2\end{array}$ & $\begin{array}{c}61.7 \pm 25.9 \\
7.0 \pm 1.2 \\
61.5 \pm 30.6 \\
8.37 \pm 1.90\end{array}$ & $\begin{array}{l}- \\
- \\
62.0 \pm 32.9 \\
14.9 \pm 12.3\end{array}$ \\
\hline $\mathrm{CL}_{\text {ren }}(\mathrm{ml} / \mathrm{min})$ & $52.7 \pm 40.7$ & $89.7 \pm 61.0$ & $20.5 \pm 12.7$ & $\begin{array}{l}27.6 \pm 9.4 \\
{[n=6]}\end{array}$ & $3.7 \pm 7.5$ & $\begin{array}{l}3.9 \pm 3.5 \\
{[n=2]}\end{array}$ \\
\hline
\end{tabular}

$\mathrm{D}$ ata are mean $\pm \mathrm{SD}$

glucose and its distribution within the creatinine clearance groups is shown in Table 3. In all five patients who had a creatinine clearance of less than $20 \mathrm{ml} / \mathrm{min}$ at baseline, only the minimum dose of $1 \mathrm{mg}$ glimepiride was required to maintain the fasting blood glucose level throughout the 3-month study period. In one of these patients, fasting blood glucose fell below $3.33 \mathrm{mmol} / \mathrm{l}$ on four separate days. A further two patients with higher baseline creatinine clearances were also well-maintained for 3 months at this minimum dose.

Of four patients with a creatinine clearance of 20 $50 \mathrm{ml} / \mathrm{min}$ at baseline, who had stable fasting blood glucose concentrations at a final dose of $2 \mathrm{mg}$ glimepiride, one patient should have received a higher dose because his fasting blood glucose remained at $12.1 \mathrm{mmol} / \mathrm{l}$ throughout the study. He continued on $2 \mathrm{mg}$ glimepiride because home glucose monitoring values were consistently below $9.7 \mathrm{mmol} / \mathrm{l}$. Three patients with baseline creatinine clearance higher than $20 \mathrm{ml} / \mathrm{min}$, including one with a value over $50 \mathrm{ml} /$ $\mathrm{min}$, required $4 \mathrm{mg}$ glimepiride daily to maintain their fasting blood glucose values. O ne of the patients in group 2, however, should have received a higher dose based on a fasting blood glucose concentration of $11.0 \mathrm{mmol} / \mathrm{l}$ on day 70 . The two patients receiving $8 \mathrm{mg}$ glimepiride had creatinine clearance values greater than $50 \mathrm{ml} / \mathrm{min}$ and were not well-controlled, their fasting blood glucose levels being over $9.99 \mathrm{mmol} / \mathrm{l}$, even after the $8 \mathrm{mg}$ dose was started on day 43.

No relevant changes were found in the individual blood glucose profiles (capillary blood) measured before and during the study. The serial assessment of serum glucose levels on pharmacokinetic study days indicated a slight increase in the mean \pm SD baseline value from $7.94 \pm\left. 3.39 \mathrm{mmol} \cdot\right|^{-1}$ on day 1 to $8.78 \pm$ $3.81 \mathrm{mmol} \cdot \mathrm{l}^{-1}$ on day 85 . The mean blood glucose level between $4-10 \mathrm{~h}$ after glimepiride administration, however, showed a tendency to fall, from $9.47 \pm$ $3.11 \mathrm{mmol} \cdot \mathrm{I}^{-1}$ on day 1 to $8.40 \pm 2.85 \mathrm{mmol} \cdot \mathrm{l}^{-1}$ on day 85. The variation in these data, though, was high. G lycosuria was only noted occasionally.

Mean serum insulin and C-peptide levels measured in serial samples taken over $24 \mathrm{~h}$ on days 1 and 85 were almost identical (data not shown). In one patient high non-specific binding was observed in the insulin radioimmunoassay, probably due to the presence of autoantibodies. Mean haemoglobin $A_{1 c}$ in whole blood was $6.96 \pm 1.28 \% 1$ month before 
A
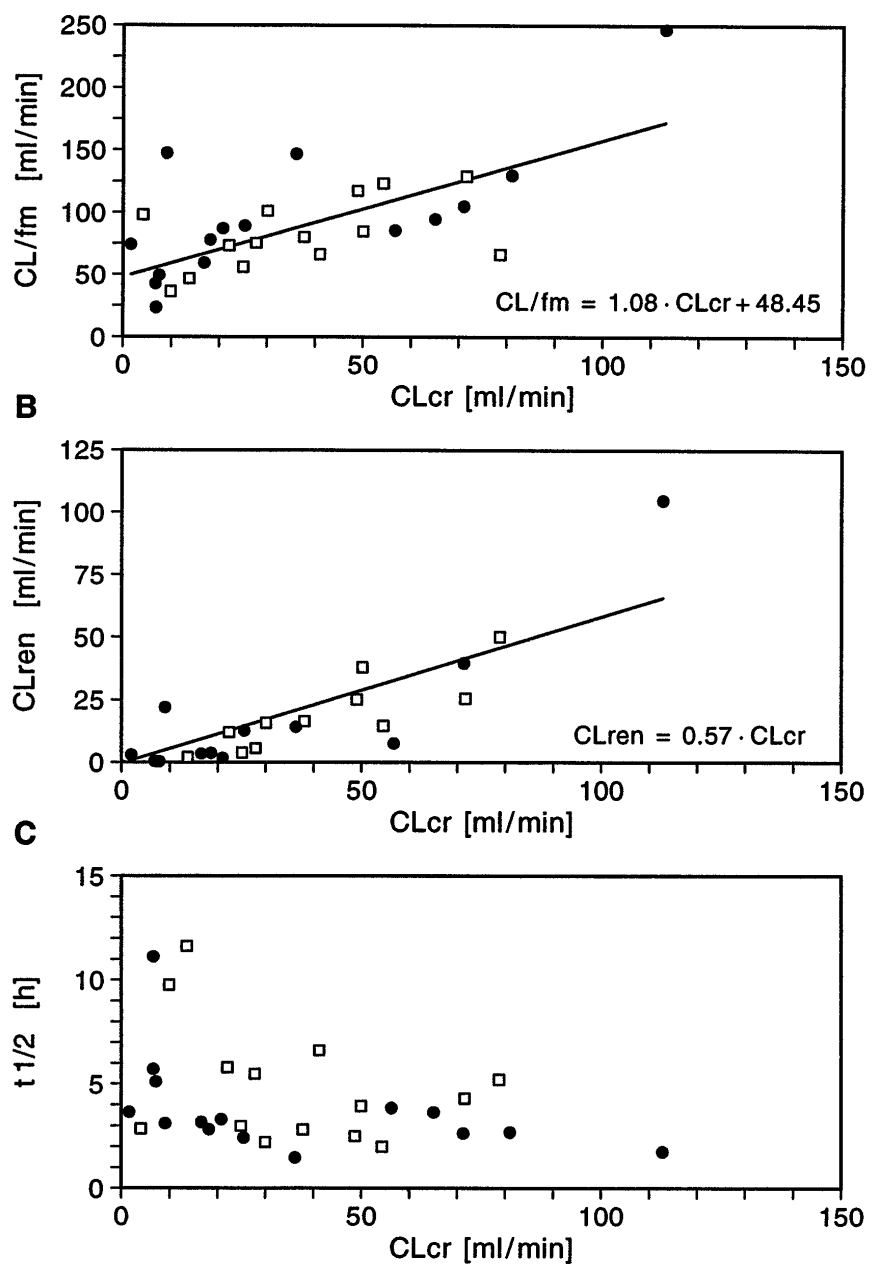

Fig. 3. A - C. R egression between creatinine clearance and apparent clearance of metabolite $\left(C L / f_{m}\right)(\mathbf{A})$, renal clearance $\left(C L_{\text {ren }}\right)(\mathbf{B})$, or terminal half-life $\left(t_{1 / 2}\right)(\mathbf{C})$ of metabolite $M 1$. Regression equation for $C L_{\text {ren }}$ extrapolated to the origin. single-dose study, $\square$ multiple-dose study

glimepiride treatment and remained stable throughout the study period, being $6.99 \pm 1.20 \%$ after 3 months' treatment, thereby reflecting the fact that the patients were in good metabolic control before starting the study.

There was no change in the $\mathrm{HbA}_{1 \mathrm{c}}$ levels measured before and at 1, 2 and 3 months after medication. The presence of glucose in the urine was only noted occasionally and ketoacidosis only noted twice during the study.

Safety. No adverse events were reported in the singledose study. In the multiple-dose study, there were two adverse events. In one patient with a history of arterial hypertension, associated with ventricular hypertrophy, with fundus hypertonicus (II), diabetic retinopathy, diabetic neuropathy and diabetic angiopathy, in addition to diabetes, diabetic nephropathy, chronic renal insufficiency and a cyst of the right kidney,
A
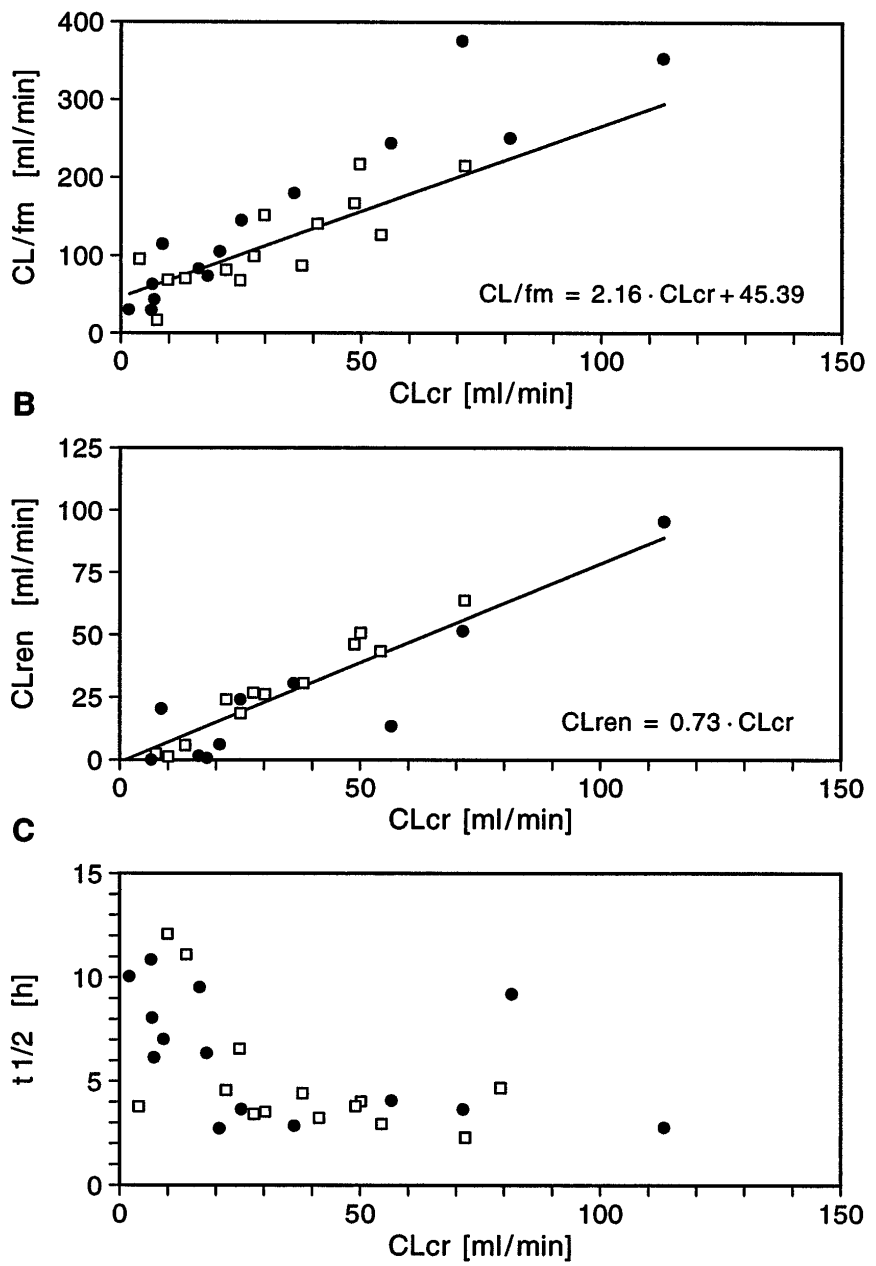

Fig. 4. A - C. R egression between creatinine clearance and apparent clearance of metabolite $\left(C L / f_{m}\right)(\mathbf{A})$, renal clearance $\left(C L_{\text {ren }}\right)(\mathbf{B})$, or terminal half-life $\left(t_{1 / 2}\right)(\mathbf{C})$ of metabolite $M 2$. Regression equation for $C L_{\text {ren }}$ extrapolated to the origin. single-dose study, $\square$ multiple-dose study

Table 3. E ffective dose of glimepiride and creatinine clearance in patients during the multiple-dose study

\begin{tabular}{llllr}
\hline $\begin{array}{llll}\text { Glimepiride } \\
\text { dose }(\mathrm{mg})\end{array}$ & $\begin{array}{l}\mathrm{Group} \mathrm{1} \\
\mathrm{CL}_{\mathrm{cr}}>50 \mathrm{ml} / \\
\min \end{array}$ & $\begin{array}{l}\mathrm{G} \text { roup 2 } \\
\mathrm{CL}_{\mathrm{cr}} 20-50 \mathrm{ml} / \mathrm{CL}_{\mathrm{cr}}<20 \mathrm{ml} / \\
\min \end{array}$ & $\begin{array}{l}\mathrm{G} \text { roup 3 } \\
\min \end{array}$ & Total \\
\hline 1 & 1 & 1 & 5 & 7 \\
2 & - & 4 & - & 4 \\
4 & 1 & 2 & - & 3 \\
8 & 2 & - & - & 2 \\
Total & 4 & 7 & 5 & 16 \\
\hline
\end{tabular}

routine ECG on the last study day followed by creatine kinase-M B revealed a "silent" myocardial infarction. The patient was transferred to the local coronary care unit and was dismissed after 17 days in good condition. The event was considered serious, but not related to the study medication. The other patient provided persistent reports of hypoglycaemia, 
which were not resolved by reducing the glimepiride dose to $0.5 \mathrm{mg}$; the patient withdrew from the study.

In both studies, laboratory values gave results which would be expected for patients with diabetes and kidney impairment. No changes were found after either single or multiple dose administration which could be directly related to the intake of the study drug.

\section{Discussion}

The results of these studies show that glimepiride is a safe and effective hypoglycaemic agent in patients with NIDDM and renal impairment. The multipledose study showed that the pharmacokinetic profile of glimepiride remained unchanged over a 3-month period in 16 diabetic patients. $D$ ata from the single and multiple dose studies revealed that the relative total clearance and the volume of distribution of glimepiride increased when creatinine clearance was less than $50 \mathrm{ml} / \mathrm{min}$. The $\mathrm{t}_{1 / 2}$ and $\mathrm{MT}$ were essentially unchanged in kidney failure.

A II sulphonylureas are strongly bound to plasma proteins, particularly to albumin [12] and glimepiride is normally more than $99 \%$ bound to serum proteins [7]. Since the unbound fraction determines many of the drug's pharmacokinetic properties, an increase in the unbound glimepiride fraction, similar to that which occurs with phenytoin in patients with kidney disease [13], could explain the increase in relative clearance of glimepiride in kidney impairment. The expected decrease in plasma $t_{1 / 2}$ could not be demonstrated, possibly because of the high variability.

In the patients with a creatinine clearance above $50 \mathrm{ml} / \mathrm{min}$, the pharmacokinetics of glimepiride were comparable to values reported in healthy male patients after oral or intravenous administration of glimepiride. In 12 healthy males given 1, 2, 4, and $8 \mathrm{mg}$ oral glimepiride, the range in mean $t_{\max }$ was 2.1-2.8 $\mathrm{h}$, in $\mathrm{t}_{1 / 2} 1.2-1.5 \mathrm{~h}$ and $\mathrm{CL} / \mathrm{f} 53.5-56.5 \mathrm{~min} / \mathrm{ml}$ [7], compared to a mean $t_{\max }$ of $1.9 \mathrm{~h}(\mathrm{~S})$, a mean $\mathrm{t}_{1 / 2}$ of $2.28(\mathrm{~S})$ and $5.6(\mathrm{M}) \mathrm{h}$, and $\mathrm{CL} / \mathrm{f}$ of $41.6(\mathrm{~S})$ and $68.1(\mathrm{M}) \mathrm{ml} / \mathrm{min}$.

The total urinary excretion of the metabolites $\mathrm{M} 1$ and M2 corrected for molecular weight and expressed as a percentage of the dose was $44.4 \%$ (S) and $40.4 \%(M)$ in patients with a creatinine clearance greater than $50 \mathrm{ml} / \mathrm{min}$, which is comparable to the values of $45.9-50.7 \%$ after oral glimepiride recorded in normal subjects $[6,7]$.

Renal clearance and total urinary excretion of glimepiride metabolites $\mathrm{M} 1$ and $\mathrm{M} 2$ were reduced in kidney failure, and as a consequence the $C_{\max }$ and $t_{1 / 2}$ increased for both metabolites. This corresponds to similar data presented on other sulphonylureas [4, 5]. The reduction in metabolite elimination may well have influenced the efficacy of the glimepiride as the metabolite M1 has been found to have hypoglycaemic potential in animal studies [10].

If the altered pharmacokinetics found in impaired kidney function are due to a reduced protein binding of glimepiride, no dose adjustment to allow for kidney impairment would be required if the pharmacokinetics of the unbound, active glimepiride were to remain unchanged. H owever, the increased exposure to the hypoglycaemia-inducing glimepiride metabolite M 1 might explain why the patients with greatest kidney impairment achieved metabolic control with the minimum dose of $1 \mathrm{mg} /$ day.

While there is a need to establish the influence of protein binding on the pharmacokinetics of glimepiride, it is effectively cleared in kidney disease with no accumulation and efficacy is good, possibly due to the pharmacological action of its metabolite $M 1$, which has an increased $C_{\max }$ and $t_{1 / 2}$ in patients with lower creatinine clearance following oral glimepiride. A lthough the half-life of glibenclamide was unchanged in patients with renal disease, accumulation of metabolites occurred which was suggested to be responsible for the prolonged hypoglycaemia reported [5]. Similarly, the prolonged elimination of the glimepiride metabolite M 1 might also cause severe hypoglycaemia in this population, although due to the rather low number of patients, this was not found in the present study.

In conclusion, glimepiride was found to be a safe and efficacious hypoglycaemic agent with definable pharmacokinetics in the present study in patients with NIDD M and renal impairment. Good metabolic control of blood glucose levels could be achieved with low doses in impaired renal function. H owever, more information will be required before the drug can be advocated for long-term use in this patient population.

A cknowledgements. We thank Prof. S. R ingoir and Prof. N.H. $L$ ameire, University of $G$ ent for participation in the clinical study, D r. K.H. Lehr for bioanalysis and D r. C. Williams and D r. M.J. Parnham, PA S, B onn, for assistance with the manuscript.

This work was supported by H oechst A G, Frankfurt, G ermany

\section{References}

1. Pearson J G, A ntal E J, R aehl CL et al. (1986) Pharmacokinetic disposition of ${ }^{14} \mathrm{C}$-glyburide in patients with varying renal function. Clin Pharmacol Ther 39: 318-324

2. Campbell D B, Gordon B H, Ings R M J et al. (1986) The effects of renal disease on the pharmacokinetics of gliclazide in diabetic patients. B r J Clin Pharmacol 21: 572-573

3. Petitpierre B, Perrin L, Rudhardt M et al. (1972) Behaviour of chlorpropamide in renal insufficiency and under the effect of associated drug therapy. Int J Clin Pharmacol 6: $120-124$

4. B alant L, Z ahnd G, G orgia A et al. (1973) Pharmacokinetics of glipizide in man: influence of renal insufficiency. Diabetologia 9: 331-338 
5. Jackson JE, B ressler R (1981) Clinical pharmacology of sulphonylurea hypoglycaemic agents: part 2. Drugs 22: 295-320

6. Badian M, Korn A, L ehr K-H et al. (1994) A bsolute bioavailability of glimepiride (A maryl) after oral administration. D rug $M$ etab D rug I nteract 11: 331-339

7. M alerczyk V, Badian M, Korn A et al. (1994) D ose linearity assessment of glimepiride (A maryl) tablets in healthy volunteers. D rug M etab D rug Interact 11: 341-357

8. Geisen K (1988) Special pharmacology of the new sulphonylurea glimepiride. A rzneim-Forsch/D rug R es 38: 11201130

9. Leclercq-M eyer V, A kkan A G, M archand J et al. (1991) E ffects of glimepiride and glibenclamide on insulin and glucagon secretion by the perfused rat pancreas. Biochem Pharmacol 42: 1634-1637

10. D onaubauer H H , M ayer D (1993) A cute, subchronic and chronic toxicity of the new sulphonylurea glimepiride in rats. A rzneim Forsch/D rug R es 43: 547-549

11. L ehr K H, D amm P (1990) Simultaneous determination of the sulphonylurea glimepiride and its metabolites in human serum and urine by high-performance liquid chromatography after pre-column derivatization. J Chromatog 526: 497-505

12. Balant L (1981) Clinical pharmacokinetics of sulphonylurea hyopglycaemic drugs. Clin Pharmacokin 6: 215-241

13. R ichens A (1979) Clinical pharmacokinetics of phenytoin. Clin Pharmacokin 4: 153-169 